\title{
A PSICOLOGIA REDESCOBRIRÁ A SEXUALIDADE?
}

Vera Paiva*

\begin{abstract}
RESUMO. O senso comum indica o psicólogo como o profissional mais preparado para trabalhar com a sexualidade. Raramente, entretanto, formamos psicólogos para lidar com a vida sexual em contextos que não sejam clínicos. Esse artigo sintetiza uma crítica às abordagens "sexológicas", dominantes no século XX, argumentando que a abordagem "construcionista", ao desconstruir a heteronormatividade e a subordinação da mulher como naturais, validou-se como paradigma alternativo de grande relevância para a pesquisa e a prática de profissionais que abordam a sexualidade. O construcionismo interpretou melhor novos desafios, como a epidemia da Aids, especialmente em contextos de desigualdade e violação de direitos, inspirando a prevenção baseada na análise de gênero e compreensão de cenários, cenas, scripts e trajetórias de sujeitos sexuais. O trabalho dos psicólogos será beneficiado se sua formação redescobrir a sexualidade, repensar a sexologia, superar abordagens baseadas em valores pessoais e em psicologias com pretensões universalistas, ao menos no campo da sexualidade.
\end{abstract}

Palavras-chave: sexo, prevenção, construcionismo social.

\section{WILL PSYCHOLOGY REDISCOVER SEXUALITY?}

\begin{abstract}
Common sense designates the psychologist the most proficient professional to work with sexuality. Rarely, though, we are educating psychologists to work with the sexual life in non-clinical contexts. This article synthesizes a critique of the "sexological" framework, hegemonic throughout the XX century, and argues that the "constructionist" approach, while deconstructing woman's subordination and hetero-normativeness as natural, was validated as an alternative paradigm of great relevance for research and professional practice approaching the sexual sphere. This theoretical framework better understood challenges as the Aids epidemic, especially in contexts of inequality and rights violations; inspired technologies for its prevention based on gender analysis and the understanding of sexual scenarios, scenes, scripts and trajectories by sexual subjects. Psychologists practice will benefit from rediscovering sexuality, surpassing approaches based on personal values, rethinking the sexological and psychological approaches that aim at universalism, at least on the sexuality domain.
\end{abstract}

Key words: Sex, prevention, social constructionism.

\section{LA PSICOLOGIA¿ REDESCUBRIRÁ LA SEXUALIDAD?}

RESUMEN. El sentido común considera al psicólogo como el profesional más preparado para dar cuenta de la sexualidad. Raramente, sin embargo, se forman psicólogos para trabajar con la vida sexual en contextos no-clínicos. Este artículo sintetiza una crítica a los abordajes sexológicas, dominantes en el siglo XX, argumentando que el abordaje construccionista, al deconstruir la heteronormatividad y la subordinación femenina como naturales, se validó como paradigma alternativo de gran relevancia para la investigación y la práctica de los profesionales que trabajan con la sexualidad. Este marco teórico comprendió mejor desafíos como la epidemia de SIDA, especialmente en contextos de desigualdad y violación de derechos; ha inspirado tecnologías para la prevención basadas en el análisis de género y la comprensión de los escenarios sexuales, escenas, guiones e trayectorias de sujetos sexuales. El trabajo de los psicólogos se verá beneficiado en su formación al redescubrir la sexualidad, superar los abordajes psicológicos con pretensiones universalistas, por lo menos en el dominio sexual.

Palabras-clave: Sexo, prevención, construccionismo social.

* Professora Livre-Docente do Departamento de Psicologia Social/ Núcleo de Estudos para a Prevenção da Aids - Universidade de São Paulo. Autora convidada. 
O senso comum indica o psicólogo como o profissional mais preparado para dar conta da sexualidade. Pelo menos assim pensam os colegas formados em outras disciplinas, com quem trabalhamos na escola, nos serviços de saúde ou nas empresas. Será? Parafraseando um texto clássico da antropóloga Carole Vance (1991/1995), nesse ensaio quero sugerir que as psicologias, e o ensino de psicologia no Brasil, precisam redescobrir a sexualidade interpelados pela fecundidade da abordagem construcionista adotada nos artigos desse dossiê neste volume 13, número 4 da Psicologia em Estudo. Começo com uma história que testemunhei entre várias outras em mais de duas décadas de trabalho como psicóloga e pesquisadora no campo da sexualidade e da Aids.

\section{A CENA DA INFECÇÃO PELO HIV}

"Não é incrível? No momento em que eu peguei o vírus da AIDS, eu não estava ali me contaminando... era muita paixão! Foi um momento de alegria, de prazer, tanto tempo desejado... Prazer corporal, mas espiritual também. Queria viver aquele meu amor, repetir outros momentos, iguais àquele" (L., 1987).

Tenho repetido por onde ando essas palavras de L., que anotei em minha agenda de 1987, no dia em que me chamou para se despedir, algumas horas antes de morrer. Como tantas outras vezes durante seu processo psicoterapêutico, conversávamos. Dessa vez num quarto de hospital, onde familiares protegidos por máscaras, luvas e aventais revezavam-se na janelinha.

Seguiu-se um silêncio estridente e emocionado, enquanto uma imagem se impunha como expressão do insight que compartilhávamos. Emoldurados por um lusco-fusco de final da tarde, via no horizonte jovens e mulheres de todas as cores e credos adoecendo, casos ainda raros na epidemia brasileira. Em visão panorâmica, cinemascope, imaginava os cenários e cenas como a de L., onde os personagens movimentavam um enredo inédito na visão amplamente compartilhada sobre a epidemia até então. Ainda se associava a epidemia do HIV aos chamados "promíscuos" - homossexuais, usuários de drogas, trabalhadores do sexo, africanos e haitianos- com a contribuição direta de profissionais e pesquisadores que usavam sua autoridade tecno-científica para construir esse sentido da AIDS, inclusive na mídia.

A pesquisa social e epidemiológica nos informava desde 1985 que uma cena como a de L. poderia ser masculina ou uma história feminina, de amor heterossexual ou homossexual, de alguém bem jovem ou de pessoas na meia idade... não sei como o leitor a imaginou. Já sabíamos que o vírus não escolhe sexo, idade, religião, classe social, país ou continente, e se expande em contextos de maior vulnerabilidade social. O que não sabíamos, entretanto, era como dar conta de modo satisfatório da intuição que L., um homem maduro e heterossexual, nos deixava de presente para pensar como conter a expansão da epidemia.

Ampliando a cena de infecção que $L$. exemplificava, minha imaginação ativa escancarava os simbolismos e o panorama social da epidemia que crescia, como numa intuição das iniciativas que deveríamos produzir para prevenir sua expansão. Como prevenir o sofrimento, ou ainda o espanto e a tensão de familiares, ou dos muitos psicólogos que o haviam rejeitado como paciente em seus consultórios? Confrontar o estigma e a discriminação era prioritário; rever radicalmente o modo como pensávamos a sexualidade e a prevenção seria fundamental. Nesse projeto, as pessoas vivendo com HIV não seriam "o problema, mas parte da solução", como o movimento de pessoas vivendo com Aids reivindicava nas ruas. $\mathrm{L}$ esboçava a solução para superar modelos de prevenção da epidemiologia comportamental.

"Quando pegamos Aids não estamos pegando Aids, estamos fazendo outra coisa...”.

Vinte anos se passaram e as pessoas que se infectaram nos contam, quando nos propomos a escutá-las nos seus próprios termos, como estavam fazendo outra coisa. Inúmeras vezes, nada amorosas ou necessariamente prazerosas, raramente "promíscuas". Em projetos de prevenção que exploraram junto com os participantes a compreensão das cenas sexuais em que não usaram o preservativo, outros sentidos apareceram, além da paixão. O rapaz de 16 anos lembrou que "estava descarregando meu desejo... antes que a porra subisse para a cabeça...”. A professora de sua escola foi categórica “...eu estava dando pra ele [marido] o que ele queria, para fazê-lo feliz e, enfim, dormir". O rapaz que participou da oficina de sexo seguro indicou a dificuldade de estar "ganhando o pão de cada dia com os homens que pintavam no escuro do cinema para fazer programa”. Uma mulher vivendo com HIV disse que "...ele estava bêbado, ia me bater, e o que eu podia fazer?”.

Depoimentos como estes ilustrariam cenas típicas "da transmissão do HIV", embora o discurso da prevenção do HIV/Aids raramente se refira ao momento da infecção pelo HIV nestes termos. Fala-se de comportamentos e práticas sexuais de risco, sem sentido, sem contexto, sem pessoa. Outros discursos 
psicológicos focalizariam o "desejo", a "defesa", "negação", "culpa", "resiliência", "atitude", "crença", "identidade", "fatores de risco". E o Sexo? Estamos formando profissionais para abordar a atividade sexual nos termos em que acontece na vida cotidiana, especialmente em contextos de pobreza e desigualdade, ou para trabalhar no contexto do Sistema Único de Saúde (SUS), na escola, no ambiente de trabalho, na comunidade?

Por mais de um século e especialmente nos últimos 50 anos, a produção de teorias e discursos sobre a sexualidade tem sido um empreendimento em constante expansão para além das tradições religiosas onde costumavam se apoiar. Nesse empreendimento, profissionais de diversas áreas têm pensado e atuado sobre temas que o discurso tecno-científico tratou de definir como questão para a prática. Duas ordens de questões acabaram por construir, sucessivamente, abordagens distintas que hoje coexistem no campo da sexualidade. Como discutiremos a seguir, a abordagem "sexológica" afirmou-se respondendo a "problemas" demográficos ou de saúde (mental ou sexual), contribuindo para produzir os discursos que Foucault chamou de bio-poder. A abordagem construcionista definiu como questão compreender a sexualidade como fenômeno social, a desigualdade entre os sexos, a subordinação das mulheres, a discriminação sexual; nas últimas três décadas dedicou-se fortemente a compreender a epidemia da Aids e a violação de direitos sexuais.

\section{O SÉCULO DA SEXOLOGIA}

John Gagnon e Richard Parker, na introdução do livro considerado um divisor de águas nesse campo (Conceiving Sexuality, 1995), dataram o primeiro período desse empreendimento de 1890 a 1980 nomeando-o de "sexológico". Segundo os autores, o período sexológico se iniciou com poucos pesquisadores e ativistas buscando trazer o discurso sobre a sexualidade para o campo da produção científica e secular, empreendimento cuja história mais longa Michel Foucault traçou até o conjunto de crenças médicas que normatizavam o controle dos impulsos sexuais no século XIX. Os autores identificam Freud (e seguidores), Ellis, Hirschfeld, Malinovsky, Stopes, Reich, pesquisadores do Instituto Kinsey, Margareth Mead, Masters \& Johnson como os principais teóricos nesse período.

Nas primeiras décadas do período sexológico, utilizava-se a entrevista clínica e histórias de vida como abordagem principal. Depois da década de
1930, os estudos descritivos com base em questionários e diversas modalidades de trabalho de campo foram introduzidos, e no período de 1960-1970 a observação e a experimentação em laboratório foram adotadas para descrever a chamada "natureza" da resposta sexual.

Durante todo esse período, coexistiram nos discursos tecno-científicos concepções sobre "a" sexualidade ancoradas nas noções de impulso, de força natural de imenso poder, poder que se opunha à civilização e à cultura. Culturas e sociedades apenas respondiam a essa força essencial, natural, essencialmente diferente entre homens e mulheres, considerada normal quando heterossexual. Com algumas nuances, esses teóricos de diferentes disciplinas concordavam que, se a ciência produzisse teorias sobre a sexualidade e revelasse sua natureza, a humanidade seria beneficiada por um maior equilíbrio entre indivíduo e sociedade ou para relações sexuais naturais e saudáveis.

As "descobertas" do período sexológico resultaram em modelos clínicos de intervenção operados por psicólogos, médicos e psicanalistas até hoje. Os autores-heróis acima identificados por Gagnon \& Parker, por exemplo, dedicavam-se à saúde mental e, depois dos anos 60, passaram a tratar também da "saúde sexual" - a normalidade biológica teria sido "revelada" pelo laboratório e a normalidade estatística pelas pesquisas sobre crenças, atitudes ou práticas sexuais de populações e grupos.

Inspirados por teorias de desenvolvimento e da personalidade que receberam a marca do período sexológico, educadores gradativamente passaram a utilizá-las como subtexto na interpretação de atitudes de jovens e crianças no ambiente escolar, ainda que raramente para tratar diretamente do tema da sexualidade ou conduzir qualquer tipo de educação sexual. A natureza do sexo e seus hormônios explicariam comportamentos menos civilizados e definiriam a "natureza rebelde" de uma etapa universal do desenvolvimento humano não descrita até então: a adolescência. A verdade sobre essa sexualidade natural e normal definiria também "a" família natural e normal. "Famílias desestruturadas" (não-naturais), para usar a linguagem que se fala na escola ou nos serviços de saúde e de assistência social, explicariam desvios de comportamento a serem tratados ou prevenidos.

Importante notar ainda, como outros textos já discutiram (Paiva, Ayres \& França Jr, 2004; Paiva, 2006) que no Brasil e em outros países latinoamericanos, os profissionais que trabalham em 
programas públicos dedicados à sexualidade jovem quase sempre atuam com base em suas crenças e valores pessoais apenas ligeiramente informados por esse discurso científico mais típico do século passado, o "sexológico", disseminado pela mídia, por políticas públicas e reinterpretado no discurso religioso, como se pode observar em outros artigos desse dossiê (Bellenzani et al., 2008; Maksud, 2008; Rios et al., 2008; Silva et al., 2008). Em outras palavras, embora atuem com base em sua autoridade técnica e científica - de psicólogos, educadores, médicos, assistentes sociais, enfermeiros, professores de primeiro e segundo grau - raramente foram formados para lidar com a sexualidade em contextos que não sejam propriamente terapêuticos. Normatizam o sexo desejável, nomeando-o como "mais saudável", baseados em valores e noções pessoais que reinterpretam a sofisticada teorização sexológica do século XX.

$\mathrm{Na}$ esfera da sexualidade, importante ressaltar, uma das grandes contribuições do período sexológico para a mudança social foi naturalizar o prazer no mundo de tradição judaico-cristã, legitimar a sexualidade independente da reprodução, separação que a pílula anticoncepcional massificou. Também descrever - como fizeram Kinsey e a epidemiologia comportamental ou a psicologia social de inspiração sócio-cognitivista pós-Aids - a prevalência maior e insuspeitada de certas atitudes e práticas sexuais. $\mathrm{O}$ prazer pôde emergir como "verdade revelada" sobre a natureza do sexo, natureza que a sociedade ocidental teria reprimido e que as sexologias poderiam desreprimir ou tratar como "disfunção.

\section{O SURGIMENTO DO PARADIGMA CONSTRUCIONISTA}

No final dos anos 60, o sexo inicia sua emancipação da essencialidade e da reprodução. A verdade sobre o sexo como vida instintiva ou impulsiva começou a ser questionada por teóricos dos movimentos feminista e homossexual que contribuíram definitivamente para a explosão de estudos no campo das ciências humanas e sociais, aprofundando a crise do paradigma sexológico. Essa perspectiva crítica tem sido chamada de construcionista (contructionism).

Como discutiu C. Vance (1991/1995) no texto clássico que inspirou o título desse artigo, de 1975 a
1990 o discurso construcionista ${ }^{1}$ re-definiu o gênero e a identidade sexual, separou a identidade das práticas sexuais, questionou o determinismo biológico, construiu a história da homossexualidade e da origem da dominação masculina. A etnografia do período expunha a evidência da diversidade dos sentidos atribuídos aos sexos e à atividade sexual, observada em todos os continentes. Além disso, a experiência visível das mulheres emancipadas da reprodução como único destino feminino e os experimentos urbanos que produziam sociabilidades e sexualidades homossexuais, também no Brasil, validavam a noção de que a vida cotidiana, histórica e socialmente construída, era re-inventável.

Desde os anos 1970, a produção feminista dedicase a questionar a inevitabilidade e a naturalidade da desigualdade entre os sexos e da subordinação feminina. A categoria gênero, contribuição definitiva da teoria feminista, foi consagrada no final do século XX como relevante categoria de análise social. Bastante citada, a historiadora Joan Scott (1995) definiu-a como constituinte das relações sociais e de poder fundadas sobre as percepções das diferenças entre os sexos.

T. Barbieri (1991), C. Vance (1991/1995), R. Parker (2000) entre outros, têm discutido como o influente ensaio de Gayle Rubin já nos anos 1970 foi fundamental para desconstruir as noções essencialistas que atribuíam à sexualidade e à reprodução a origem da desigualdade de gênero. G. Rubin (1975) discutiu que a noção de patriarcado, chave para a compreensão feminista da histórica opressão das mulheres, não explicaria as desigualdades de gênero presentes nos mais diferentes contextos socioculturais. Retomou criticamente a inspiração de Engels, Levi-Strauss e Freud sobre os operadores da estruturação e reprodução social e apresentou, então, o sistema sexo/gênero como "um conjunto de medidas mediante o qual a sociedade transforma a sexualidade biológica em produto da atividade humana e essas necessidades sexuais transformadas são satisfeitas" (Rubin, 1975). Em outro artigo seminal (Rubin, 1984/1999) propôs que, embora imbricados, sexo e gênero são domínios distintos, constituem sistemas distintos e exigem teorias próprias. Observou como as classificações da sexualidade (heterossexual ou homossexual ou bissexual) também hierarquizam o sexo bom/mal,

\footnotetext{
A tradução desse texto de C. Vance na revista Physis usa construtivismo. Preferimos construcionismo usado também por outros autores, também para não confundir com outros construtivismos, inclusive da pedagogia de Paulo Freire que frequentemente aparece no debate sobre prevenção e educação sexual.
} 
normal/anormal, natural/não-natural. Ainda que matizem as relações de gênero, essas categorias possuem lógicas e efeitos muito próprios.

Jeffrey Weeks (2000) usa o termo construcionismo social para descrever essa abordagem, historicamente orientada, que pretende compreender atitudes em relação ao corpo e à sexualidade, apreendendo as relações de poder que modelam o que se define como normal e anormal. Chama de "Sexo" (maiúscula) o termo descritivo para as diferenças anatômicas básicas, internas e externas, que diferenciam o homem da mulher; chama de "gênero" a diferenciação social entre homens e mulheres; de "sexualidade" uma "descrição geral para série de crenças, comportamentos, relações e identidades socialmente construídas e historicamente modeladas relacionadas ao que Foucault denominou "o corpo e seus prazeres" (Foucault, 1984). Weeks definiu o construcionismo social em oposição ao essencialismo que pretende explicar as propriedades de um todo complexo por referência a uma suposta essência anterior.

Henrietta Moore (1997) radicalizou a análise das práticas discursivas e seus efeitos sobre os corpos. Defendeu que a categorização binária da existência de dois gêneros (masculino e feminino) seria também efeito de um discurso, ocidental, portanto histórica e culturalmente específica. Não seria possível definir "a" mulher e "o" homem, pois existem homens e mulheres modelados por contextos sociais distintos. A noção de um "sexo" (com $\mathbf{s}$ minúsculo) entendido como uma propriedade biológica apartada de qualquer construção social configuraria justamente o discurso biomédico específico da cultura ocidental.

Como diria Castells (1999), a sexualidade tem sido uma das áreas mais profícuas para investigar, na dinâmica social, as intrincadas relações entre processo de modernização e permanência das lógicas tradicionais, no plano das práticas e no plano dos valores. Os estudos sobre sexualidade deram uma contribuição definitiva às ciências sociais e ao movimento que expôs a conformação social do mundo privado, terreno por excelência da psicologia, conformação com características simultaneamente locais e globais, como a dinâmica da epidemia da Aids.

Ao invés de pensar que o sexo teria prioridade na explicação do comportamento, da cultura, da civilização e da sociedade (interpretado com base em regras de parentesco, libido, repressão e tabus) passouse a pensar como a atividade sexual (física e simbólica) poderia configurar outras atividades sociais, expressando conjugalidade, trabalho, política, negócio ou religião. Como insistiu J. Weeks ao longo de sua obra: qualquer coisa pode ser sexualizada, nada seria intrinsecamente sexual.

Inúmeros teóricos do campo construcionista têm chamado a atenção para a natureza intersubjetiva da sexualidade e dos significados sexuais, que à semelhança de outras atividades sociais, produzem a experiência subjetiva e a vida cotidiana de homens e mulheres. A sexualidade não se restringe à dimensão reprodutiva nem à psíquica, não pode ser considerada como propriedade de indivíduos isolados e atomizados, está impregnada de simbolismos compartilhados que constroem excitação e satisfação erótica (Heilborn, 1999; Parker, 1994). Essa perspectiva e a compreensão do contexto e da dinâmica das interações sociais, do impacto do estigma e da discriminação associados à orientação sexual (homofobia) e às relações de gênero (machismo), da expressão encarnada dos diferenciais de poder e seus determinantes macro-sociais (também a pobreza e racismo), têm sido reconhecidas na literatura deste século XXI como necessárias para a produção de ações para promover e proteger direitos, promover saúde sexual ou prevenir o HIV.

Desde a psicologia, temos dialogado com alguns dos autores desse campo, discutindo como caminhos pessoais constantemente ampliam os dois gêneros para variadas formulações sobre $o$ feminino e masculino, singularidades mais salientes nos cenários sócio-culturais em que se já se afirmou o indivíduo como um sujeito psicológico e de direito (Paiva, 1990, 2000, 2006). As diferentes tradições culturais (como as religiosas, ver Rios et al., 2008), configuradas em estruturas e contextos sócio-econômicos específicos (como as comunidades receptoras de turismo, ver Bellenzani et al., 2008) constituem uma visão de nossa própria transitoriedade e virtual multiplicidade na realização das sexualidades e dos gêneros. Invenções locais, como as que encontramos encarnadas em homens e mulheres de nosso cotidiano, ou que se realizam em redes menos visíveis como as homossexuais (Parker, 2002), povoam a mídia e internet e descrevem vivamente a possibilidade de sujeitos sexuais, como discutiremos adiante, conduzirem sua constante reinvenção.

Os modelos teóricos de construção social do gênero e da sexualidade, de qualquer maneira, variam na sua radicalidade. Vance (1991/1995) observou que o construcionismo mais radical considera que até o desejo sexual é construído pela cultura e pela história a partir das energias e capacidades do corpo; não 
existiria, portanto, “impulso" ou "pulsão sexual”, não se assumiria que funcionamentos ou sensações fisiológicas sejam intrínsecos, nem talvez necessários. Uma posição mais moderada aceita implicitamente um desejo inerente que será construído em atos, identidade, comunidade e escolha de objeto. Algumas abordagens antropológicas disseminaram, de 1920 a 1990, relatos que ilustravam a diversidade de costumes sexuais e seus sentidos em várias sociedades, fundamentados no sexo biologicamente determinado e estável subjetivamente. Vance chamouos de "modelos de influência cultural" ressaltando que, embora se digam construcionistas, mantém a fusão sexo e gênero entre outros elementos essencialistas não examinados.

Muitos autores consideram que essa mudança no modo de compreender os sexos, a dominação e o poder provocou a mais importante ruptura epistemológica no campo das ciências sociais no final do século $\mathrm{XX}$. Seria injusto atribuí-la exclusivamente a Michel Foucault, que certamente produziu nesse processo o trabalho definitivo e mais conhecido sobre a sexualidade (História da Sexualidade, 1976/1988, 1984/1990). Abordando a sexualidade no contexto de sua obra sobre saber e poder, Foucault superou o desconforto provocado por essa área de investigação quase marginal ao mainstream acadêmico, associada ao feminismo e à crítica homossexual. (Vance, 1991/1995) Antes da obra de Foucault, entretanto, o construcionismo social americano de Simon \& Gagnon e de Rubin já influenciava a produção marginalizada e a história da sexualidade em vários continentes era profícua como reflexão sobre a gênese da subordinação feminina ou como história da homossexualidade (ver por exemplo, Barbieri, 1991, McIntosh, 1968, Parker, 2000, Weeks, 1977).

\section{A PSICOLOGIA SOCIAL DE MEAD}

Do ponto de vista da redescoberta da sexualidade pela psicologia e, mais especialmente, para informar processos de trabalho no campo da sexualidade no âmbito de uma psicologia necessariamente social, vale a pena notar a forte presença da inspiração da obra de George Mead (1934/1992) no campo construcionista, mais conhecida do estudante de psicologia brasileiro nas obras de P.Berger e T.Luckmann e de J.Habermas.

Mead afirmava, no início do século XX, que separados da sociedade seríamos ao mesmo tempo "mudos" e "desprovidos de mente". Por outro lado, nem o sujeito nem a situação social constituiriam a realidade primária, mas se constituem em e por meio de práticas simbólicas reiteradas ${ }^{2}$ Haverá sempre mais realidade "disponível" que a efetivamente interiorizada no processo de socialização com a mediação dos “outros significativos" encarregados, na primeira infância, da nossa apreensão do mundo como dotado de sentido. Um indivíduo será sempre produto da interação recíproca de muitos outros. Nas brincadeiras e jogos na infância, temos que interpretar o sentido do contexto e suas regras para agir, interiorizando-o ao assumir ou presumir o lugar do outro nos dramas encenados cotidianamente. Os papéis acionados pelos atores são suas interpretações das normas culturais, dos mitos e das formas de conhecimento encarnadas nas pessoas em ação (não são, portanto, respostas automáticas a estímulos, impulsos ou normas sócio-culturais que o sujeitam e reprimem). Enquanto self o ser humano age construindo sua ação enquanto interage com os outros.

O self, como a sociedade para Mead, é processo e não substância. Cada experiência social é responsável pelo aparecimento do self, que não existe independentemente dessa experiência. $\mathrm{O}$ alcance da auto-consciência se dá por meio do outro, requer se colocar no lugar do "outro generalizado", do surgimento do outro no self. A inovação será fruto do fluxo ininterrupto da consciência espontânea da individualidade ${ }^{3}$ (do "I") relacionada à individualidade que foi configurada ou moldada pela sociedade (ao "Me"). O self é processo que ocorre na relação do $\mathrm{Me}$ (mim) com o I (eu).

O self é conversação e linguagem que originaramse nos gestos. A mente surgiria da comunicação, da conversação de gestos no processo social que constitui o contexto da experiência. A comunicação discursiva permanece ocorrendo integrada ao gesto. Pensar é comunicação, conversação entre o indivíduo e o "outro generalizado".

A sociedade humana, insistimos, não carimba simplesmente os padrões de seu comportamento organizado nos seus membros individuais como padrão do self individual; ao mesmo tempo lhe dá uma mente (mind) que lhe permite conversar

Coelho Jr e Figueiredo (2004) chamam atenção para um texto de 1910 (What social objects must psychology pressupose?), onde G. Mead, antes de Husserl publicar sobre intersubjetividade, pensava a sociedade como realidade subjetiva e a noção de um Outro na formação do self.

3 Robert Farr (1872/1954) entende que o "I" poderia se aproximar do "ID" de Freud. Considero mais adequado associá-lo ao inconsciente coletivo de Jung, melhor definido como virtualidade não vivida que como reprimido. 
conscientemente consigo mesmo nos termos das atitudes sociais.(...) Sua atividade mental permite ao indivíduo imprimir o desenvolvimento de seu self e, em certo grau, modificar, nos termos de seu self, o padrão geral do comportamento social e do grupo nos termos dos quais seu self foi originalmente constituído (Mead, 1992, p. 263. Tradução da autora).

Um século depois, como discutem Manuel Castells (1999) e Arjun Appadurai (1996/2003), multiplicaram-se os discursos significativos que pariticipam da conversação e da socialização; diferentes discursos disputam a atenção do sujeito, em todos os continentes. A cultura não pertence a um povo, não está apenas localizada no espaço (de um discurso científico, de um ritual religioso ou de uma obra de arte) e mobiliza um arquivo virtual de diferenças que são conscientemente utilizadas pela fantasia individual. Como imaginação coletiva a cultura disseminada massivamente tem sido combustível para ação e inovação (Appadurai, 2003, p. 1-23). O trabalho da imaginação depende muito da memória; mas a tem substituído pela pluralidade dos mundos sincronica e coletivamente imaginados, como no caso das culturas sexuais.

Fazemos colagens de tradições culturais (que prefiro à noção de Cultura) e de realidades rituais e normativas, especialmente na esfera da sexualidade. Ou seja, a imaginação social do "sujeito sexual" permanece interpelada por diferentes discursos sobre a sexualidade e a cada contexto intersubjetivo - seja como agente das lutas sociais, sujeito dos discursos por direitos (Parker, Barbosa \& Aggleton, 1999), seja como sujeito autônomo e consciente de suas intenções naquela cena e interação social específica, carregadas de sentidos (Paiva, 2000, 2006). Cidadãos com autonomia podem ser sujeitos de muitos discursos sobre o sexo, às vezes contraditórios (como o religioso e o da prevenção com preservativo). Vivemos a pluralidade do sujeito que deve multiplicar sua agilidade na mobilização de scripts distintos, em diferentes cenas.

Outros autores, também dedicados a compreender a dimensão performativa (e fragmentária) da subjetivação têm valorizado a obra de G. Mead pela sua ancestral intuição sobre o que chamou de "personalidade múltipla" implicada em cada uma das distintas relações que estabelecemos ao produzir nossa vida (no mundo do trabalho, na família, na igreja, no sindicato). Enrique Malo, por exemplo, ao pensar nas subjetividades de classe articuladas à dominação de gênero, discutirá que não haveria apenas um "outro generalizado", mas vários "outros generalizados que constituem nossos auditórios interiorizados, aos quais replicamos" (Malo, 2007, p. 17). Essa perspectiva nos permitiria chegar a uma concepção que transcende a da unidade do sujeito pressuposta em muitas teorias de mudança.

Superando a ancestralidade de Mead, autores construcionistas enfatizam o simbólico nas interações sociais ancorando-as nos macro-determinantes que reproduzem a desigualdade na vida social - nas relações raciais e de gênero especialmente. Nas organização das ações pela equidade, a sexualidade é concebida como atividade social, portanto, como sinergia ou conflito de "outros generalizados".

\section{AS TEORIAS INTERPELADAS PELA AIDS: A SEXUALIDADE NÃO SE REDUZ AO DISCURSO OU AO COMPORTAMENTO}

A emergência do HIV/Aids foi definitiva para estimular a crítica mais radical aos paradigmas sexológicos ou de influência cultural. Contribuiu, então, para a crítica da epidemiologia comportamental que importava para a Aids a tradição dos estudos sócio-cognitivos no campo da psicologia da saúde (sobre stress e comportamento alimentar, p. ex.), rapidamente identificados como insuficientes para dar conta da dinâmica da epidemia, especialmente em contextos de desigualdade e pobreza. (Parker, 1994, 2000; Paiva, 2000, 2006)

Os dedicados infectologistas e dermatologistas fundadores do primeiro programa de Aids das Américas (na Secretaria Estadual da Saúde de São Paulo, em 1983), convidaram epidemiologistas, psicólogos e "sexólogos" (que trabalhavam com disfunção sexual e planejamento familiar) para a pensar a prevenção. Na década seguinte, J. Mann (1992), então diretor do Programa Global de Aids, estimulava diretamente a produção da pesquisa social em sexualidade e saúde reprodutiva para repensar a prevenção de novas infecções pelo HIV; no Brasil começavamos a adotar e aprimorar o quadro da vulnerabilidade que J. Mann defendia. ${ }^{4}$ Essas

\footnotetext{
Um dos projetos apoiados, o Working Group for Sexual Behavioral Research (WGSBR), incluia R. Parker, J. Gagnon, G. Herdt, C. Greenblat, P. Agletton. B. Zalduando, G. Herdt, P. Mane, M. Tan, M. Bronfman, R. Barbosa e V. Paiva. De 1991-1995, essa rede de construcionistas formou pesquisadores da AIDS dos 5 continentes nas teorias e metodologias construcionistas Desde os anos 1990 várias revistas acadêmicas de impacto valorizam especialmente a produção construcionista: "Culture, Health and Sexuality", "Reproductive Health Matters", "Sex Education", "Global Public Health", "Sexuality Research \& Social Policy".
} 
iniciativas incluíam pessoas vivendo com Aids e grupos mais fortemente afetados, espelhando a tradição construcionista social que valoriza o movimento social como formulador de teoria.

$\mathrm{Na}$ segunda década da epidemia, o desafio brasileiro foi derivar da pesquisa e reflexão crítica construcionista abordagens e tecnologias para os processo de trabalho em prevenção da Aids. A obra de Gagnon e Simon (1973) foi, então, fundamental. Discutiram que a raiz biológica do comportamento sexual não é mais expressiva que em outras formas de comportamento (como o modo de alimentar-se ou jogar xadrez).

Como vários outros autores do campo construcionista, foram inspirados pelo interacionismosimbólico e pelo pragmatismo norte-americanos (como em Goffman e George Mead), pela sociologia do conhecimento (de Kuhn e Berger \& Luckman), pela antropologia cultural-interpretativa (de Geertz), pelas estratégias dramático-interpretativas de $\mathrm{K}$. Burke.

Em recente entrevista, J. Gagnon afirmou que reduzir as coisas a textos e discursos seria um erro de Foucault, na medida em que a vida social consiste de atuações e interações, de pessoas atuando em espaços sociais. Indicou que a noção de scripts $^{5}$ para a conduta sexual que sua obra introduziu "aproxima-se mais do performativo que do discurso" (Gagnon, 2006, p. 416). Ao pensar a atividade sexual o autor começou pela situação psicossexual, pensando-a como um processo em cujas contingências as pessoas assimilam estilos de vida e, ao colocá-los em prática, modificam o eu. Num segundo momento, abordou o mundo intersubjetivo da cultura, os "cenários culturais" definidos por ele como "o sistema semiótico de instruções que é o espaço intersubjetivo do sóciocultural" (p. 410). Os arranjos sociais onde a sexualidade se realiza comporiam uma matriz que teria, num eixo, os eventos roteirizados ("scripts") e, em outro eixo, os "atores".

Todas as instituições e arranjos institucionalizados podem ser vistos como sistemas de signos e símbolos através dos quais as exigências e as práticas de papéis específicos são dados. (...) Estes cenários raramente são preditivos por completo do comportamento real, e eles são geralmente muito abstratos para serem aplicados em

5 Prefiro atualmente não traduzir a palavra script como roteiro. Script, palavra incluída nos dicionários da língua portuguesa, indica mais diretamente a inspiração dramatúrgica e ao mesmo tempo a noção de "prescrição" que mantém em inglês. quaisquer circunstâncias". A falta de congruência entre o cenário abstrato e a situação concreta é resolvida pela "criação de scripts inter-pessoais". Adicionalmente, a reorganização simbólica da realidade, de forma a se perceber inteiramente os desejos partilhados e multifacetados do ator, é criada pelo "script intra-psíquico", "a fantasia no mais rico sentido da palavra" (Simon \& Gagnon, 1999, p. 29-30. Tradução da autora).

Dos atores, portanto, se exige agilidade para, em cada situação concreta, escolher linhas de ação diante de crescentes possibilidades no mundo público, e para dar conta da integridade de suas fantasias (que chamaram de scripts intra-psíquicos). "A tarefa do ator é ligar, adaptar, transformar e estabilizar continuamente o inter-pessoal e o cultural, mantendo a plausibilidade do eu" (Gagnon, 2006, p. 413).

A experiência brasileira com a prevenção do HIV e da Aids, de promoção da saúde e dos direitos sexuais, nos estimulou a ampliar a noção de cena sexual e a descrição de cenários culturais e redes relacionais da obra de Gagnon e colaboradores (Antunes 2005; Bellenzani et al., 2008; Paiva 2000, 2006; Rios et al., 2008; Silva et al., 2008). Nas tecnologias desenvolvidas em diversos projetos, incorporamos o psicodrama de Jacob Moreno, a pedagogia de Paulo Freire e a dramaturgia de Augusto Boal.

Observamos, então, que a esfera da sexualidade em um mesmo cenário cultural, como diriam Simon e Gagnon, estabelece uma esfera específica da cultura, delineia guias singulares para a experiência sexual de um grupo, que alguns chamariam de "subcultura sexual"; preferimos chamar essa esfera singular da cultura de "cenário sexual". Grupos de jovens brasileiros religiosos, vivendo em comunidades turísticas ou jovens homossexuais, por exemplo, realizam sua sexualidade em diferentes cenários sexuais do mesmo cenário socio-cultural paulista no início desse século XXI. Ou seja, cotidiano de alguém que mora em São Paulo inclui vários "outros generalizados"; um cenário sexual específico, entretanto, marcará mais fortemente o espaço e tempo único de cada cena sexual (seu palco, a dinâmica,os scripts sexuais de cada ator, seus gestos e falas).

O contexto estrutural-econômico e tradição cultural específica - seja religiosa (Rios et al., 2008; Silva et al., 2008) étnica, identitária ou territorial (Antunes, 2005; Bellenzani et al., 2008), ou ainda, típicos de uma atividade profissional constroem um cenário sexual. Por exemplo, uma mesma boléia de caminhão pode ser palco de diferentes cenas do 
cenário sexual do mundo do caminhoneiro; ali fazem sexo com a esposa, com a amante, ou com uma prostituta. Analisando os scripts eróticos (Parker, 1994; 2002) compartilhados por caminhoneiros brasileiros, observamos que mais provavelmente praticavam sexo anal apenas com a amante e usavam preservativo numa freqüência significativamente maior com a prostituta que, por sua vez, raramente era beijada (Villarinho et al., 2002). A mesma pessoa (ator deste cenário) encenará scripts distintos no mesmo palco, a boléia, dependendo do ator, sentido e dinâmica da cena. Os scripts que compõem o cenário sexual do caminhoneiro, trabalhando em rotas curtas de um dia ou em rotas que exigem muitos dias fora de casa, eram os mesmos.

Aprendemos que a dinâmica de uma cena é única, nunca será igual no curso da vida de uma mesma pessoa. No planejamento de políticas publicas reconhecemos, como outros autores (Heilborn, 1999), que no mesmo contexto sócio-cultural e trajetória pessoal, muitas cenas serão parecidas.

\section{SUJEITOS EM CENA: A PESSOA EM CONTEXTO E O CONTEXTO NA PESSOA}

Colaborando com cada sujeito para adensar a narrativa de suas cenas, o profissional trabalhando nessa abordagem construcionista estimulará a descrição do espaço, do ritmo da ação de todos os personagens e seus scripts- o que cada personagem/ator faz, fala ou sente e como significa a ação e os outros personagens. A riqueza de detalhes sobre práticas, falas e interações em cena facilita acessar a espontaneidade, a fala menos presa aos discursos normativos, guardando a inspiração das tecnologias psicodramáticas inauguradas por J. Moreno. A exploração desta inter-subjetividade dramatúrgica permite ampliar detalhes da vida cotidiana, decodificar desejos, experiências prévias, recursos pessoais e comunitários, descobrir personagens onipresentes (pais, ex-parceiros, o pastor da igreja), ou crenças e valores encarnados em personagens. Permitirá também identificar desigualdades, relações de poder, avaliar o acesso a informação, a insumos, a serviços e observar o desrespeito ou violação de direitos relevantes em diversos cenários, palcos e interações intersubjetivas.

Como discutimos mais detalhadamente em outros textos (Paiva, 2000, 2006), cenas densamente descritas são um valioso recurso metodológico que pode ser coproduzido numa entrevista, na resposta a um questionário, narradas ou dramatizadas em abordagens individuais ou em grupo, em redações e trabalhos escolares, compartilhada num encontro clínico com um nutricionista, ginecologista, infectologista ou num centro de atenção à saúde. Em projetos com comunidades têm sido encenadas ou discutidas em oficinas, filmadas, gravadas ou relatadas em diário de campo depois de observação etnográfica; construídas pela pessoa que fez parte dela, ou a imaginou, ou a observou. (ver também Antunes, 2005; Bellenzani et al., 2008; Paiva et al., 2004; Rios et al., 2008; Santos \& Paiva, 2007; Silva et al., 2008; Tunala, 2005).

A descrição densa de uma cena é a entrada para o diálogo com o sujeito, para a observação da sua espontaneidade com contexto. Num programa de ação comunitária, cenas narradas ou dramatizadas têm estimulado a compreensão dos obstáculos sócioculturais e políticos para agir segundo as decisões e opções das pessoas (usar preservativo, ter ou não ter filhos, abster-se de sexo). Frequentemente deriva-se dessa abordagem a ação coletiva em defesa de direitos naquela comunidade (acesso a tratamento, ao preservativo, à informação), fomentando a compreensão dos sujeitos de como suas interações, scripts e experiências cotidianas são produzidas. Pressupõe-se, portanto, que existe uma esfera de ação para o sujeito sexual, um domínio do sujeito-cidadão, agente da negociação consciente com discursos disponíveis sobre os sexos e, ao mesmo tempo, portador de direitos (à saúde, à autonomia, à dignidade, à não-discriminação). $\mathrm{O}$ diálogo estabelecido com os sujeitos a partir de cenas concretas (ou verossímeis e imaginadas pelos participantes) facilitará a compreensão dos seus cenários sexuais e das desigualdades que organizam a experiência sexual.

Adotando a perspectiva construcionista, a ampliação da consciência será um objetivo prático mais interessante que substitui com vantagem a noção de saúde sexual frequentemente concebida como "natureza revelada" pelo discurso biomédico, ou como uma definição fechada de sucesso técnico (aumento do uso de camisinha) que contrasta com um "problema" (a vulnerabilidade ao HIV) (Paiva et al., 2004). Saúde sexual deverá ser "uma" noção a ser construída na interação entre o sujeito-técnico (especialista em educação, saúde) e a pessoa ou comunidade em questão (os especialistas na vida cotidiana que interessa abordar). Uma comunicação efetiva permitirá que o pensar informado pela normalidade técnica dialogue com a normatividade compartilhada em cada local, dialogue com "outros generalizados".

Essa abordagem tem permitido que valores pessoais de cada sujeito e os diversos sentidos para o sexo compartilhados em um cenário sexual imaginado nesse nosso tempo (como os diversos cenários homoeróticos) ou resultante de tradições culturais 
(como as religiosas), encontrem espaço de expressão no debate com técnicos e profissionais, para mútua fertilização. Essas referências têm estimulado os psicólogos, entre outros profissionais, a abandonarem a tentação de encontrar uma tecnologia fechada e universal para algo que reconhecemos ser dependente dos diversos sentidos atribuídos à sexualidade por contextos socioculturais e políticos distintos, e em cada fase da vida, fases cujos sentidos podem variar drasticamente se considerarmos a classe social, as relações raciais e de gênero como construções sociais, além de cada discurso e tradição cultural, inclusive as inventadas recentemente.

\section{PALAVRAS FINAIS}

A produção feminista internacional dedicou-se a demonstrar que a desigualdade entre os sexos, a dominação masculina e a subordinação feminina não são atribuíveis à biologia. O "gênero" como categoria de análise legitimou-se no século XXI em todas as áreas de investigação social e da saúde. Do sexo biológico (XY ou XX) não se deriva a essência natural do feminino, do masculino ou a hetero-normatividade. A produção construcionista no campo da sexualidade obteve um impacto revolucionário sobre as noções do que é natural, universal ou essencial. Redescobrir essa sexualidade socialmente construída será inovador e produtivo para as psicologia sociais ou para as diversas teorias psicodinâmicas vigentes desde o século XX que sustentam pretensões universalistas.

Nesse quadro gostaríamos que a psicologia redescobrisse a sexualidade. A produção brasileira no campo da sexualidade é particularmente abundante e influente internacionalmente no campo das ciências sociais e está bastante sintonizada com essa mudança de paradigma. A sexualidade tem sido redescoberta por vários psicólogos brasileiros que mantém a perspectiva crítica do construcionismo e que esse espaço não permite celebrar, apenas mencionar. ${ }^{6}$ Seria muito bom se a formação em psicologia lhes desse o espaço que merecem preparando os psicólogos para trabalhar com os desafios do século XXI.

6 Além dos que citei diretamente alguns psicólogos -autores desenvolvem uma obra que o leitor pode buscar: Anna Uzziel; Benedito Medrado; Fernando Teixeira; Gabriela Calazans; Jorge Lira; Karla Adrião; Luciana Vieira; Marco A. Prado; Margareth Arilla; Nilo Fernandes; Simone Monteiro; Veriano Terto Jr ; Wiliam Peres; entre muitos outros. Também psicanalistas como Jurandir Freire Costa e Luiz Toledo. São vários os periódicos especialmente dedicados a esse campo no Brasil; os mais influentes são Revista Estudos Feministas e Cadernos Pagú.

\section{REFERÊNCIAS}

Antunes, M. C. (2005). Territórios de vulnerabilidade ao HIV: homossexualidades masculinas em São Paulo. Tese de Doutorado, Instituto de Psicologia, Universidade de São Paulo, São Paulo.

Appadurai, A. (2003). Modernity at large: Cultural dimensions of globalization. Minnesota: University of Minnesota. (Original work published 1996).

Barbieri, T. (1991). Sobre a categoria gênero: Uma introdução teórico-metodológica. Em S. Azeredo \& V. Stolcke (Orgs.), Direitos reprodutivos (pp. 26-45). São Paulo: Fundação Carlos Chagas.

Bellenzani, R., Blessa, C., \& Paiva, V. (2008). Scripts em cena: HIV e mercado sexual no contexto turístico. Psicologia em Estudo, 13(4), 653-662.

Castells, M. (1999). O poder da identidade. (A era da Informação, Vol. II). Rio de Janeiro: Paz e Terra.

Coelho Jr., N. E., \& Figueiredo, L. C. (2004). Figuras da intersubjetividade na constituição subjetiva. Interações, $I X(17)$, 9-28.

Farr, R. (1988). As raízes da psicologia social moderna (18721954). Petrópolis: Vozes.

Foucault, M. (1988). A vontade de Saber. (História da Sexualidade, Vol. 1). Rio de Janeiro: Graal. (Original publicado em 1976).

Foucault, M. (1990). O uso dos prazeres (História da Sexualidade, Vol. 2). Rio de Janeiro: Graal. (Original publicado em 1984).

Gagnon, J., \& Simon, W. (1973). Sexual conduct. London: Hutchinson.

Gagnon, J., \& Parker, R. (1995). Concieving Sexuality. In J. Gagnon \& R. Parker (Eds.), Conceiving Sexuality: Approaches to sex research in a postmodern world (pp. 3-19). New York: Routlegde.

Gagnon, J. (2006). Uma interpretação do desejo: ensaios sobre o estudo da sexualidade. Rio de Janeiro: Garamond.

Heilborn, M. (1999). Sexualidade: olhar das ciências sociais. Rio de Janeiro: Jorge Zahar.

Maksud, I. (2008). Sexualidade e Mídia: discursos jornalísticos sobre o "sexual" e vida privada. Psicologia em Estudo, 13(4), 663-671.

Mann, J., Tarantola, D. J., \& Netter, T. W. (Eds.). (1992). Aids in the world. Cambridge: Harvard University.

Malo, E. M. (2007). Las dimensiones fragmentaria y performativa de las subjetividades de clase. Universitas Psychologica, Bogotá, 6(11), 11-25.

McIntosh, M. (1968). The homosexual role. Social Problems, 16, 182-192.

Mead, G. (1992). Mind, Self, and Society. Chicago: University. (Original work published 1934).

Moore, H. (1997). Understanding Sex and gender. In T. Ingold (Ed.), Companion Encyclopedia of Anthropology. London: Routledge.

Paiva, V. (1990). Evas, Marias Liliths. As voltas do feminino. São Paulo: Brasiliense.

Paiva, V. (2000). Fazendo arte com a camisinha. São Paulo: Summus. 
Paiva, V., Ayres, J. R., \& França-Jr, I. (2004). Expanding the flexibility of normative patterns in youth sexuality and prevention programs. Sexuality Research \& Social Policy (Journal of NSRC), 1(1), 83-97.

Paiva, V. (2006). Analisando cenas e sexualidades: a promoção de saúde na perspectiva dos direitos humanos. Em C. F. Cáceres, M. Petcheny, T. Frasca \& G. Careaga (Orgs.), Sexualidad, estigma y derechos humano: Desafios para el acceso a la salud en América Latina (pp. 23-52). Lima: FASPA/UPCH.

Parker, R. (1994). Diversidade sexual, análise cultural e a prevenção da Aids. Em R. Parker (Org.), A construção da solidariedade: Aids, sexualidade e política no Brasil (pp. 117-132). Rio de Janeiro: ABIA/Relume-Dumará.

Parker, R., Barbosa, R. M., \& Aggleton, P. (1999). Framing the sexual subject: The Politics of Gender, Sexuality, and Power. California: University.

Parker, R. (2000). Cultura, economia política e construção social da sexualidade. Em G. L. Louro (Org.), O corpo educado: pedagogias das sexualidades (pp. 125-150). Belo Horizonte: Autêntica.

Parker, R. (2002). Abaixo do Equador. Rio de Janeiro: Record.

Rios, L. F., Paiva, V., Maksud, I., Oliveira, C., Cruz, C. M., Santos, C. G., Terto Jr., V, \& Parker, R. (2008). Os cuidados com a "carne" na socialização sexual dos jovens. Psicologia em Estudo, 13(4), 673-682.

Rubin, G. (1975). The traffic in women: Notes on the political economy of sex. In R. Reiter (Ed.), Toward an Anthropology of Women (pp. 157-210). New York: Monthly Review.

Rubin, G. (1984). Thinking Sex: Notes for a Radical Theory of the Politics of Sexuality. In C. Vance (Ed.), Pleasure and Danger: Exploring Female Sexuality, (pp. 267-319). New York: Routledge \& Kegan, Paul.
Santos, A. O., \& Paiva, V. (2007). Vulnerabilidade ao HIV: turismo e uso de álcool e outras drogas. Revista de Saúde Pública, 41, $80-86$.

Scott, J. W. (1995). Gênero: uma categoria útil de análise histórica. Educação e Realidade, 20(2), 71-99.

Silva, C. G., Santos, A. O., Licciardi, D., \& Paiva,V. (2008). Religiosidade, juventude e sexualidade: entre a autonomia e a rigidez. Psicologia em Estudo, 13(4), 683-692.

Simon, W., \& Gagnon, J. (1999). Sexual Scripts. In R. Parker \& P. Aggleton (Eds.), Culture, society and sexuality: A reader. London: UCL.

Tunala, L. (2005). Promoção de saúde e reeducação alimentar num hospital. Tese de Doutorado, Instituto de Psicologia, Universidade de São Paulo, São Paulo.

Vance, C. (1991/1995). A antropologia redescobre a sexualidade: um comentário teórico. Physis: Revista de Saúde Coletiva, 5(1), 7-31.

Villarinho, L., Bezerra, I., Lacerda, R., \& Paiva, V. (2002). Caminhoneiros de rota curta e sua vulnerabilidade ao HIV. Revista de Saúde Pública, 36(4), 61-67.

Weeks, J. (1977). Coming out: Homosexual politics in Britain from the nineteenth century to the present. London: Quartet Books.

Weeks, J. (2000). O corpo e a sexualidade. Em G. L. Louro (Org.), O corpo educado: pedagogias das sexualidades (pp. 35-83). Belo Horizonte: Autêntica.

Recebido em 15/08/2008 Aceito em 28/10/2008

Endereço para correspondência : Vera S. F.Paiva. Av. Prof. Mello Moraes, 1721, Cidade Universitária, CEP 05508-030, São Paulo-SP. E-mail: veroca@usp.br 